\title{
Immunochemical and Molecular Characterization of Anti-RNA Polymerase I Autoantibodies Produced by Tight Skin Mouse
}

\author{
Shinobu Shibata, Tai Muryoi, Yukiko Saitoh, Teodor-D. Brumeanu, Constantin A. Bona, and Kuppuswamy N. Kasturi \\ Department of Microbiology, Mount Sinai School of Medicine, New York 10029-6574
}

\begin{abstract}
Autoantibodies against nuclear proteins like RNA polymerase I (RNA pol I) are produced in a number of rheumatic autoimmune diseases. Production of antibodies specific for the 190KD subunit of RNA pol I appears to be characteristic in the patients with systemic sclerosis. Previous investigations have shown that the tight skin (TSK) mouse is an experimental model for systemic sclerosis. In the present study we show that the TSK mice produce high titers of anti-RNA pol I antibodies, both of IgM and IgG classes. To characterize the immunochemical properties of these antibodies we obtained a large panel of hybridomas from these mice. Analysis of these hybridomas revealed that clonal frequency of autoreactive $B$ cells specific for RNA pol I are higher in the TSK mice than in the controls. mAbs obtained from the TSK mice were specific for the 190kD subunit and cross-reacted with Esherichia coli and phage T7 RNA polymerases (155-, 150-, and 107-kD polypeptides). We have also demonstrated that these antibodies bind better to the phosphorylated enzymes. The anti-RNA pol I mAbs were divided into three groups in terms of their functional property. The first group of antibodies increased the catalytic activity of the enzyme whereas the antibodies of the second group inhibited the enzymatic activity. Competitive inhibition RIAs showed that these two groups of antibodies bound to distinct epitopes. The third group of antibodies was neutral and had no activity on the enzyme function. These results suggest that TSK mouse anti-RNA pol I antibodies recognize three or more conserved epitopes. To understand the molecular basis of the generation of such autoreactive antibodies we analyzed their $\mathrm{V}$ gene repertoire. Northern analysis of RNAs of 14 TSK hybridomas showed that the $V_{H}$ genes encoding these antibodies were mainly from $V_{H} J 558$ family. It is possible that these genes were derived from a single germline gene or from a set of related genes of a single subgroup. (J. Clin. Invest. 1993. 92:984-992.) Key words: monoclonal antibody $\bullet \mathrm{V}$ gene $\bullet$ progressive systemic sclerosis • autoantigen • tight skin mouse
\end{abstract}

\section{Introduction}

Autoimmune diseases are commonly associated with the production of antibodies against nuclear and cytoplasmic en-

Address correspondence to Constantin A. Bona, Department of Microbiology, Box 1124, Mount Sinai School of Medicine, New York, NY 10029.

Received for publication 20 October 1992 and in revised form 23 March 1993.

J. Clin. Invest.

(c) The American Society for Clinical Investigation, Inc.

0021-9738/93/08/0984/09 \$2.00

Volume 92, August 1993, 984-992 zymes. Production of autoantibodies against pyruvate dehydrogenase complex in primary biliary cirrhosis (1), antithyroid peroxidase antibodies in Hashimoto's disease (2), antiglutamic acid dehydroxylase antibodies in insulin-dependent diabetes (3), anti-transfer RNA synthetase antibodies in polymyositis (4), and anti-HK ATPase antibodies in pernicious anemia (5) are well known. Autoantibodies against RNA polymerase I (RNA pol I $)^{1}$ have been described in systemic lupus erythematosus (SLE), RA, mixed connective tissue disease (MCTD) (6), and systemic sclerosis (7). Similarly these autoantibodies were also found in MRL/lpr mice that develop lupus- and arthritis-like syndromes (8). Mammalian RNA pol I is a complex enzyme composed of six to eight subunits and has an associated protein kinase NII activity (9). The subunit specificity of anti-RNA pol I autoantibodies is characteristic for a given systemic autoimmune disease. For example, the antibodies present in RA bind primarily to subunit 1 (S1) whereas SLE sera react with S2 and S5 subunits. Antibodies present in MCTD patients bind only to $S 4$ and, in certain cases, also bind to S3 and S5 (6). In SLE, it has also been shown that these antibodies react better with phosphorylated enzyme than with the native enzyme (10).

During the last few years we have studied the production of autoantibodies in tight skin (TSK) mouse, the experimental model for systemic sclerosis, which develops cutaneous hyperplasia accompanied by histopathological alterations and increased transcription of collagen genes $(11,12)$. We have shown that TSK mice produce anti-topoisomerase I (topo I) antibodies spontaneously (13), which are characteristically found only in patients with progressive systemic sclerosis (PSS) but not in patients with CREST syndrome or morphea (14). Interestingly, we have also found that anti-topo I mAbs obtained from the TSK mice and systemic sclerosis patients exhibited the same fine specificities and shared an interspecies crossreactive idiotype (15). The aim of the present study was to determine whether the TSK mice produce anti-RNA pol I antibodies, to study the frequency of autoreactive B cells, and to identify the subunits recognized. The data presented here show that anti-RNA pol I autoantibodies are present in elevated levels in the sera of TSK mice. Frequency of the hybridomas producing anti-RNA pol I antibodies is higher in the TSK mice than in the controls. In addition, we show that these autoantibodies bound to epitopes present on the 190-kD subunit of mammalian RNA pol I, on two larger subunits of Escherichia coli RNA polymerase, and on T7 RNA polymerase. These mAbs also exhibit an increased binding to the phosphorylated enzyme and show either inhibitory or enhancing effect on the enzymatic activity of RNA polymerase.

1. Abbreviations used in this paper: MCTD, mixed connective tissue disease; NCF, nitrocellulose; PSS, progressive systemic sclerosis; RNA pol I, RNA polymerase I; topo I, topoisomerase I; TSK, tight skin. 


\section{Methods}

Mice. TSK and C57BL/6 pa/pa mice were purchased from Jackson Laboratory (Bar Harbor, ME).

Antigens. Rat RNA pol I was purified from Morris hepatoma 3924A cell lysate as described (16) (kindly provided by Dr. K. Rose, University of Texas Medical School, Houston, TX). Fractions of S100 cell lysate obtained from affinity chromatography on phosphocellulose column, exhibiting high enzyme activity (17), were used as mouse RNA pol I (kindly provided by Dr. B. Sollner-Webb, John Hopkins School of Medicine, Baltimore, MD). Poly(A) polymerase, E. coli, and T7 RNA polymerases were obtained from Pharmacia LKB Biotechnology Inc. (Piscataway, NJ). Rat type II collagen was a gift from Dr. R. Holmdahl (Uppsala University, Uppsala, Sweden). Centromere recombinant protein was kindly provided by Dr. N. Rothfield (University of Connecticut School of Medicine, Farmington, CT).

$m A b s$. Spleen cells from 2-, 8-, and 16-mo-old TSK and control $\mathrm{pa} / \mathrm{pa}$ mice, either stimulated in vitro with LPS $(25 \mu \mathrm{g} / \mathrm{ml})$ for $2 \mathrm{~d}$ or unstimulated, were fused with SP2/0 myeloma cells as previously described (18). Supernatants from the hybridomas were tested for the binding specificity to RNA pol I and centromere proteins by solidphase RIA. Briefly, microtiter plates were coated with $5 \mu \mathrm{g} / \mathrm{ml}$ of rat RNA pol I or centromere protein in carbonate buffer, $\mathrm{pH} 9.6$, at $4^{\circ} \mathrm{C}$ overnight. After washing, the plates were blocked with $1 \%$ BSA in PBS,

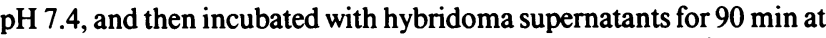
room temperature. After extensive washing, $50,000 \mathrm{cpm}$ of ${ }^{125}$ I-labeled rat monoclonal anti-mouse $\kappa$ antibody was added and incubated for a further $90 \mathrm{~min}$ at room temperature. The bound radioactivity was measured in an automatic gamma counter (Pharmacia LKB Biotechnology Inc.). Positive hybridomas were cloned under stringent limiting dilution conditions ( 0.5 cell per well) and the supernatants were retested. At least one clone for each positive hybridoma was selected and expanded. Antibodies were purified from the culture supernatants using a rat monoclonal anti-mouse $\kappa$ chain antibody coupled-Sepharose $4 \mathrm{~B}$ column as previously described (18). The isotypes were determined using $\left[{ }^{3} \mathrm{H}\right]$ rabbit anti-mouse light- and heavy chain-specific antibodies as previously described (19).

RIAs. Microtiter plates were coated with rat hepatocyte RNA pol I, E. coli, and T7 RNA polymerases and the control antigens such as BSA and collagen II at $5 \mu \mathrm{g} / \mathrm{ml}$. The binding activity of the purified mAbs was determined by RIA as described above. Preliminary experiments were carried out to determine the concentration of $\mathrm{mAbs}$ giving $50 \%$ of maximal binding to $E$. coli RNA polymerase $(5 \mu \mathrm{g} / \mathrm{ml})$-coated microtiter plates. Antibodies at concentrations corresponding to $50 \%$ of their maximal binding to antigen (RNA polymerase)-coated wells were preincubated with various amounts of collagen II, poly(A) polymerase, $E$. coli RNA polymerase, and rat hepatocyte RNA pol I. After 30 min of incubation the mixtures were transferred to $E$. coli RNA polymerase-coated plates and the inhibition of the binding was determined.

Methods for phosphorylation and dephosphorylation of enzymes. Purified T7 and $E$. coli RNA polymerases were incubated in the presence of $30 \mathrm{mM}$ cold ATP or $1 \mu \mathrm{M} \gamma-\left[{ }^{32} \mathrm{P}\right] \mathrm{ATP}$ in phosphorylation buffer ( $5 \mathrm{mM} \mathrm{MgCl}_{2} ; 50 \mathrm{mM}$ Tris- $\mathrm{HCl}, \mathrm{pH} 7.5$; and $0.5 \mathrm{mM}$ dithiothreitol) for $30 \mathrm{~min}$ at $30^{\circ} \mathrm{C}$. The reaction was stopped by cooling on ice. Enzymes phosphorylated with cold ATP were used as antigen in RIA. Both native and $\gamma-\left[{ }^{32} \mathrm{P}\right] \mathrm{ATP}$-phosphorylated enzymes were run on SDS-PAGE. ${ }^{32} \mathrm{P}$-labeled enzymes were blotted to nitrocellulose filter and autoradiographed. Polyacrylamide gels containing the control native enzymes were silver stained to determine the total number of polypeptides present in each enzyme preparation. Dephosphorylation was carried out on solid phase. Briefly, the purified enzymes were coated onto microtiter plates $(5 \mu \mathrm{g} / \mathrm{ml})$ and blocked with $1 \%$ BSAPBS. The enzyme-coated plates were then incubated with bacterial alkaline phosphatase $(50 \mathrm{U} / \mathrm{ml})$ in $1 \mathrm{M}$ diethanolamine- $0.5 \mathrm{mM}$ $\mathrm{MgCl}_{2}$ buffer for $1 \mathrm{~h}$ at room temperature. The plates were washed and the antibody binding was determined by RIA.

Immunofluorescence studies. Chromatographically purified TSK mAbs and serum samples from scleroderma patients with high titers of antinucleolar antibodies were used in this study following the methods previously described $(7,20)$. Briefly, the antibodies were first screened on slides containing Hep2 cells (Bion, Clark Ridge, IL). Antibodies reactive with these cells were further tested on Vero cells, nontreated or treated for $18 \mathrm{~h}$ with $5 \mu \mathrm{g} / \mathrm{ml}$ of colcemid or for $4 \mathrm{~h}$ with $0.2 \mu \mathrm{g} / \mathrm{ml}$ of actinomycin D. After treatment with the drugs cells were fixed with ice-cold acetone/methanol 3:1 for $3 \mathrm{~min}$ and incubated for $1 \mathrm{~h}$ in a humid chamber at room temperature with various concentrations ( 1 , $3,10,30$, and $100 \mu \mathrm{g} / \mathrm{ml})$ of murine $\mathrm{mAb}$ or human serum $(1: 100)$. Slides were then washed with PBS and incubated with 1:50 dilution of fluorescein-conjugated goat $\mathrm{F}\left(\mathrm{ab}^{\prime}\right)_{2}$ anti-mouse or human $\operatorname{Ig}$ (Jackson ImmunoResearch Laboratories, Inc., West Grove, PA). After extensive washing, the slides were mounted in Fluoromount-G (Southern Biotechnology Associates, Birmingham, AL) and examined with fluorescent epi-illumination.

Western blotting. Native and phosphorylated samples of the enzymes were electrophoresed on $7-15 \%$ polyacrylamide gradient gels using discontinuous buffer system. The separated polypeptides were transferred onto nitrocellulose (NCF) membranes, blocked with $5 \%$ nonfat dry milk in PBS, and then incubated with anti-RNA pol I mAbs for $2 \mathrm{~h}$ at room temperature. After washing, the membranes were developed with [ $\left.{ }^{125} \mathrm{I}\right]$ anti-mouse $\kappa \mathrm{mAb}$ and exposed overnight onto Kodak $\mathrm{X}$-OMAT films at $-70^{\circ} \mathrm{C}$.

Determination of the effect of TSK mouse mAbs on RNA polymerase enzymatic activity. The standard assay for RNA synthesis was modified and used for determining the effect of TSK mouse mAbs on RNA polymerase activity. Various amounts of purified $E$. coli RNA polymerase was incubated with poly(dT)poly (dA) as template DNA ( $80 \mu \mathrm{g} /$ $\mathrm{ml}$ ) for $30 \mathrm{~min}$ at $30^{\circ} \mathrm{C}$ in the reaction mixture $(40 \mathrm{mM}$ Tris- $\mathrm{HCl} ; 10$ $\mathrm{mM} \mathrm{MgCl} ; 0.1 \mathrm{mM}$ EDTA; $150 \mathrm{mM} \mathrm{KCl} ; 0.1 \mathrm{mM}$ dithiothreitol; 0.5 $\mathrm{mg} / \mathrm{ml} \mathrm{BSA}$; and $150 \mu \mathrm{M}$ ATP, CTP, GTP, and UTP) containing 0.42 $\mu \mathrm{M}\left[{ }^{3} \mathrm{H}\right] \mathrm{UTP}$ in a final volume $60 \mu \mathrm{l}$. The reaction was stopped by cooling on ice and the mixtures were transferred onto DE81 filter discs. Filters were washed four times with $5 \% \mathrm{Na}_{2} \mathrm{HPO}_{4}$, twice with distilled water, and once with ethanol. The incorporation of radioactive label was measured in the liquid-scintillation counter (Pharmacia LKB Biotechnology Inc.). The amount of the enzyme that gives $50 \%$ of maximal incorporation was preincubated with various amounts of TSK mAbs ( $15 \mathrm{~min}$ at $30^{\circ} \mathrm{C}$ ) and the RNA-synthesizing activity of the enzyme was compared with a similar amount of the enzyme that was not preincubated with $\mathrm{mAbs}$.

Extraction of RNA and Northern analysis. Total cellular RNA was extracted from $3-5 \times 10^{7}$ cells using the guanidium thiocyanate method and Northern analysis was done as previously described (21). Briefly, $10 \mu \mathrm{g}$ of the total RNA was electrophoresed on $1 \%$ agaroseformaldehyde gel and blotted onto NCF using 20x SSC (1× SSC $=0.15 \mathrm{M} \mathrm{NaCl}$ and $0.015 \mathrm{M}$ sodium citrate) as described (21). The NCFs were baked at $80^{\circ} \mathrm{C}$ in a vacuum oven for $2 \mathrm{~h}$ and prehybridized for $4 \mathrm{~h}$ at $42^{\circ} \mathrm{C}$ with prehybridization solution. The blots were hybridized with the hybridization solution (prehybridization solution containing $10 \%$ dextran sulphate and $2 \times 10^{6} \mathrm{cpm} / \mathrm{ml}$ of random primed $\mathrm{V}_{\mathrm{H}}$ or $\mathrm{V}_{\mathrm{K}}$ probe) overnight at $42^{\circ} \mathrm{C}$, washed twice with $2 \times \mathrm{SSC}$ containing $0.1 \%$ SDS at room temperature for $15 \mathrm{~min}$, and washed twice with $0.2 \times$ SSC containing $0.1 \%$ SDS at $65^{\circ} \mathrm{C}$ for $15 \mathrm{~min}$. NCF blots were dried and autoradiographed on Kodak X-OMAT-AR film, at $-70^{\circ} \mathrm{C}$ for $1-3 \mathrm{~d}$.

$V$ gene probes. The $\mathrm{V}_{\mathrm{H}}$ gene family probes $\left(\mathrm{V}_{\mathrm{H}} \mathrm{X} 24, \mathrm{~V}_{\mathrm{H}} 36-09\right.$, $\mathrm{V}_{\mathrm{H}} \mathrm{J} 606, \mathrm{~V}_{\mathrm{H}} \mathrm{J} 558, \mathrm{~V}_{\mathrm{H}} \mathrm{GAM}, \mathrm{V}_{\mathrm{H}} 11, \mathrm{~V}_{\mathrm{H}} \mathrm{S} 107, \mathrm{~V}_{\mathrm{H}} \mathrm{QPC} 52$, and $\mathrm{V}_{\mathrm{H}} 7183$ ) and $V_{K}$ gene family probes $\left(V_{K} 1, V_{K} 2, V_{K} 4, V_{K} 8, V_{K} 9, V_{K} 10, V_{K} 19\right.$, $V_{K} 21, V_{K} 22, V_{K} 23, V_{K} 24$, and $V_{K} 28$ ) were prepared as described elsewhere (18). The lack of crosshybridization of these probes was previously demonstrated (22-24).

\section{Results}

Presence of anti-RNA pol I autoantibodies in TSK mice sera. The presence of autoantibodies to RNA pol I in the sera of 8and 16-mo-old TSK and C57BL/6 pa/pa mice was determined by RIA. In the preliminary experiments various dilu- 
tions of sera were assayed to determine the optimal dilution. IgG and IgM antibodies bound to RNA pol I-coated wells were revealed using ${ }^{125} \mathrm{I}$-labeled rabbit $\mathrm{F}\left(\mathrm{ab}^{\prime}\right)$ anti-mouse $\gamma$ or $\mu$ antibodies. The data depicted in Fig. 1 show that the titers of IgM anti-RNA pol I antibodies were elevated in 31 of 35 TSK mice and the IgG antibodies were elevated in 12 of 35 mice tested. The level of anti-RNA pol I antibodies in the serum was significantly higher in the TSK mice than in $\mathrm{pa} / \mathrm{pa}$ mice $(P$ $<0.05$ in IgG and $P<0.01$ in IgM).

Frequency of hybridomas producing anti-RNA pol I antibodies. Since the TSK mice have high levels of anti-RNA pol I antibodies in their sera, we prepared a large panel of hybridomas and selected the clones producing anti-RNA pol I antibodies to study immunochemical and molecular characteristics of anti-RNA pol I autoantibodies. The frequency of B cell clones producing antibodies to RNA pol I was studied using hybridomas obtained from 2-, 8-, and 16-mo-old TSK or 16mo-old pa/pa mice. Among 350 hybridomas obtained from TSK mice, $6 \%$ exhibited binding activity to RNA pol I but none showed binding to centromere protein. On the other hand, from 147 hybridomas derived from pa/pa mice, only $1.4 \%$ showed RNA pol I binding activity (Table I).

From the panel of 21 hybridomas producing anti-RNA pol I, 14 hybridomas secreting antibodies showing high binding activity were recloned and further characterized. 11 clones produced IgM antibodies (116A7-11, L179-7, L272-8, L341-11, L342-11, L435-4, M25-4, M31-1, M51-0, M61-34, and M9432 ) and 3 clones produced IgG antibodies (GM3-24, GM5-7, and GM38-26).

Characterization of TSK mice anti-RNA pol I mAbs. The presence of anti-RNA pol I antibodies in the sera of patients with systemic sclerosis (7) or other rheumatic diseases (6) and in MRL mice (8) was studied using rat hepatocyte RNA pol I (25). In this study, besides the rat enzyme, we have used bacterial ( $E$. coli) and viral (T7 phage) enzymes, since it is well known that self-epitopes on housekeeping enzymes (15), structural proteins (26), and cell receptors (27) are conserved during the phylogeny. From the panel, $14 \mathrm{mAbs}$ were tested for their binding activity to RNA polymerases from various sources. In this experiment we have also tested the binding of
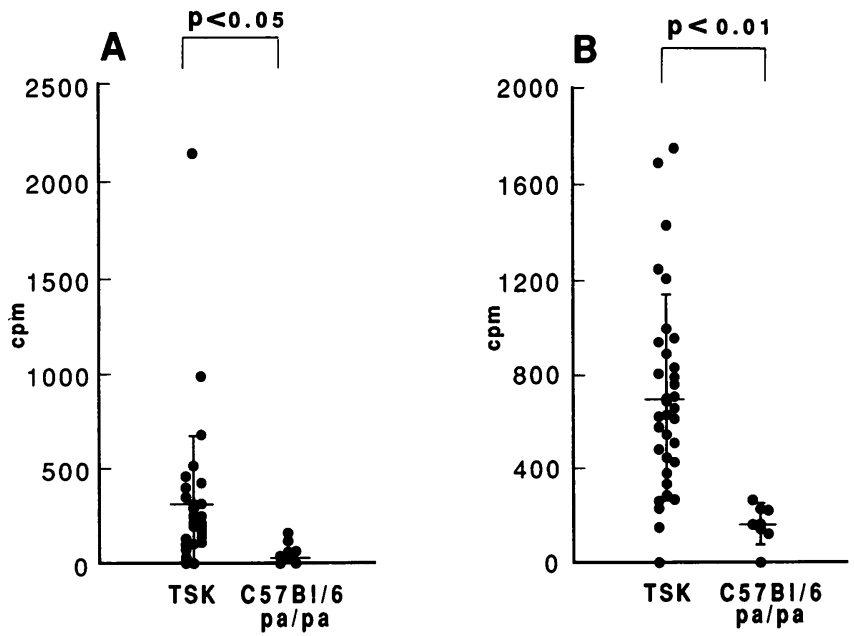

Figure 1. Serum anti-RNA pol I antibody activity in TSK and C57B1/6 pa/pa mice. $(A)$ IgG antibodies; $(B)$ IgM antibodies. The antibody levels were determined by RIA (see Methods) and the binding activities are presented as bound cpm. Each point represents an individual serum at 1:50 dilution ( $35 \mathrm{TSK}$ and $7 \mathrm{pa} / \mathrm{pa}$ mice).
Table I. Clonal Frequency Analysis of TSK Hybridomas

\begin{tabular}{lcccc}
\hline \multicolumn{1}{c}{ Origin of cells } & $\begin{array}{c}\text { In vitro } \\
\text { stimulus }\end{array}$ & $\begin{array}{c}\text { Number of } \\
\text { hybridomas } \\
\text { tested }\end{array}$ & $\begin{array}{c}\text { Number of } \\
\text { anti-RNA pol I } \\
\text { (\% clonal frequency) }\end{array}$ & $\begin{array}{c}\text { Number of } \\
\text { anticentromere }\end{array}$ \\
\hline 2-mo-old TSK & LPS & 231 & $9(3.9)$ & 0 \\
8-mo-old TSK & - & 13 & $1(7.8)$ & 0 \\
8-mo-old TSK & LPS & 54 & $8(14.8)$ & 0 \\
16-mo-old TSK & LPS & 52 & $3(5.8)$ & ND \\
16-mo-old pa/pa & - & 51 & $1(2.0)$ & ND \\
16-mo-old pa/pa & LPS & 96 & $1(1.0)$ & ND \\
\hline
\end{tabular}

serum polyclonal antibodies from rabbits (nonimmunized or immunized with rat RNA pol I) and from humans (normal subjects and PSS patients) as controls. Representative results are shown in Fig. $2 \mathrm{~A}$. A majority of the TSK antibodies reacted with all three enzymes tested. The rabbit immune serum and PSS sera also recognized all the enzymes. Normal rabbit and human sera did not bind significantly to any of these enzymes (see the legend to Fig. 2).

In previous reports it has been shown that the autoantibodies against rat hepatoma RNA pol I were highly specific and did not cross-react with poly(A) polymerase (25). Therefore, we have examined whether the TSK mAbs also exhibit a similar property by competitive inhibition assays. This was determined by competitive inhibition assays using poly $(\mathrm{A})$ polymerase as an inhibitor. All the mAbs were specific for RNA polymerase. The results obtained with representative mAbs GM5-7 (IgG) and M61-34 (IgM) are shown in Fig. 2, B and C. E. coli and rat RNA pol I showed higher inhibition than poly(A) polymerase. The control antigen collagen II did not show any inhibitory activity. These data indicate that the TSK mouse autoantibodies do not cross-react with poly (A) polymerase, similar to human autoantibodies. These results also suggest that the rat and $E$. coli RNA polymerases might share common epitopes.

Binding of TSK $m A$ bs to phosphorylated and dephosphorylated RNA polymerases. Previous studies have shown that antibodies present in SLE showed enhanced binding to the phosphorylated enzyme (10). Conversely, dephosphorylation of the enzyme decreased the binding of lupus anti-RNA pol I as much as $50 \%(10)$. Therefore, we have investigated the effect of phosphorylation and dephosphorylation on the binding of TSK mouse mAbs. Since it has been shown that rat RNA pol I has associated protein kinase activity, we attempted to label the rat enzyme with $\gamma \mathrm{ATP}$ in an in vitro phosphorylation reaction. But we could not succeed in phosphorylating the rat enzyme. It is possible that the associated protein kinase activity was lost during the purification procedure since rat RNA pol I also did not show any RNA synthesizing activity (data not shown). Therefore, $\mathrm{T} 7$ and $E$. coli enzymes were used in this experiment. T7 RNA polymerase preparation showed strong phosphorylation ( ${ }^{32} \mathrm{P}$ radiolabeling) of a $107-\mathrm{kD}$ band (data not shown) and $E$. coli RNA polymerase exhibited phosphorylation of 150- and 155-kD bands (data not shown).

The binding of TSK mouse mAbs to phosphorylated and dephosphorylated enzymes as determined by RIA is shown in Fig. 3. The results are expressed as a binding unit (one binding unit is the mean cpm of triplicates, which represents the binding of a given mAb to native enzyme). A majority of the TSK mouse mAbs (five of seven) showed a significant increase in their binding activity to phosphorylated $E$. coli and T7 RNA polymerases, whereas there was no significant change in their 

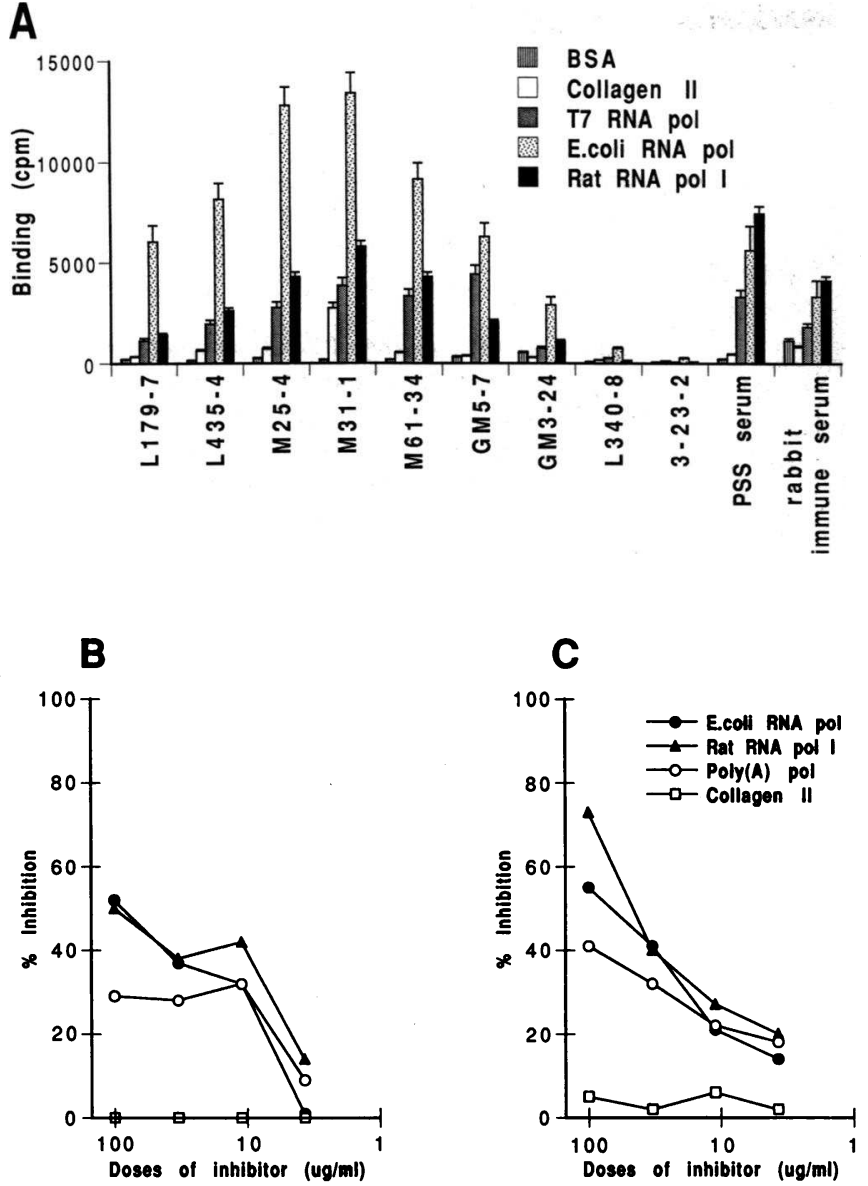

Figure 2. Characterization of the TSK mouse anti-RNA pol I mAbs. $(A)$ Direct binding assay: the binding activity of TSK mAbs $(5 \mu \mathrm{g} /$ $\mathrm{ml}$ ), human (1:200), and rabbit (1:100) sera to various RNA polymerases was determined by RIA. The binding of human and rabbit sera was revealed with [ ${ }^{125}$ I] protein A. Collagen type II and BSA were used as control antigens and L340-8 and 3-23-2 mAbs represent isotype-matched IgM and IgG controls. The columns represent the average binding of triplicate assay expressed as $\mathrm{cpm} \pm \mathrm{SD}$. The reactivity of healthy human and nonimmunized rabbit sera to RNA polymerases was not significant compared with that of PSS and immune rabbit sera. (Binding of the normal human serum to rat RNA pol I, E. coli, and T7 RNA polymerases was $611 \pm 54,647 \pm 83$, and $337 \pm 27 \mathrm{cpm}$, respectively. Binding of normal rabbit serum was $633 \pm 82,738 \pm 49$, and $582 \pm 54 \mathrm{cpm}$ to the same set of enzymes.) (B) Competitive inhibition of the binding of GM5-7 mAb (IgG). (C) Competitive inhibition of the binding of M61-34 mAb (IgM). The amount of mAbs showing 50\% maximal binding in the direct binding assays were preincubated for with various amounts of inhibitors (rat, $E$. coli RNA polymerase, poly(A) polymerase, and collagen type II) and the mixtures were transferred to $E$. coli RNA polymerase-coated wells. The bound cpm was counted and the results are shown as percentage of inhibition of the binding.

binding to dephosphorylated enzymes. Negative control mAbs, devoid of binding activity to RNA polymerase, did not show any significant binding to either phosphorylated or dephosphorylated enzymes (data not shown). These results clearly demonstrate that TSK mouse mAbs bind better to the phosphorylated form, similar to human autoantibodies.

Immunofluorescence studies. In this study we compared the immunofluorescence patterns obtained from TSK mAbs and scleroderma sera having high titer of speckled type antinu-

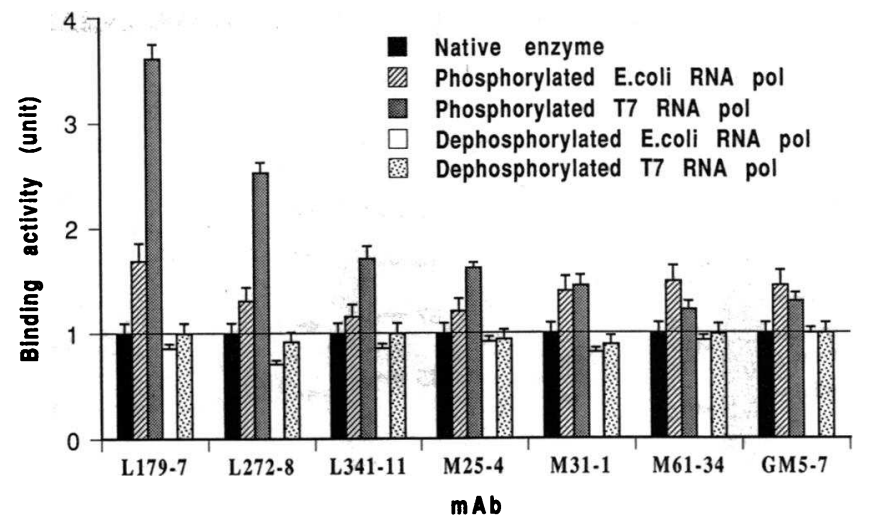

Figure 3. Effect of phosphorylation and dephosphorylation of RNA polymerase on the binding activity of TSK mAbs. Purified $E$. coli and T7 RNA polymerases were phosphorylated using their own protein kinase activity. Dephosphorylation was done using calf alkaline phosphatase (see Methods). The binding of mAbs to these antigens was measured by RIA and the results were expressed as binding units. One binding unit is the quantity of the $\mathrm{mAb}$ that binds to the native enzyme under the experimental conditions used (see Methods).

cleolar antibodies and anti-RNA pol I antibodies. All four mAbs tested exhibited a similar pattern of staining, and representative results are shown in Fig. 4. TSK mAbs stained the nucleoli of Hep2 cells strongly (Fig. $4 A$ ) whereas the control BALB/c mAb (specific for IDA10 idiotype) did not exhibit any nucleolar staining (Fig. $4 \mathrm{~B}$ ). Colcemid-treated Vero cells incubated with TSK mAbs showed bright fluorescence spots in
A
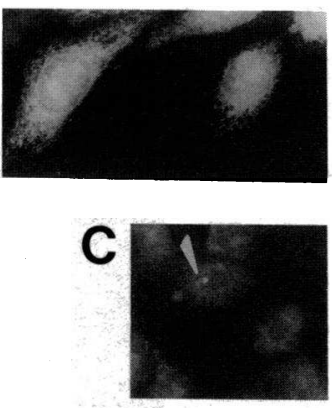

D

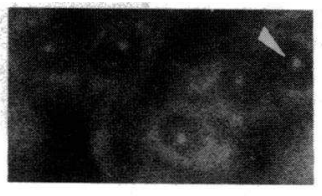

E

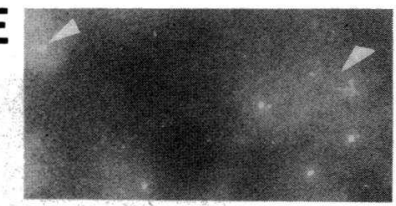

B
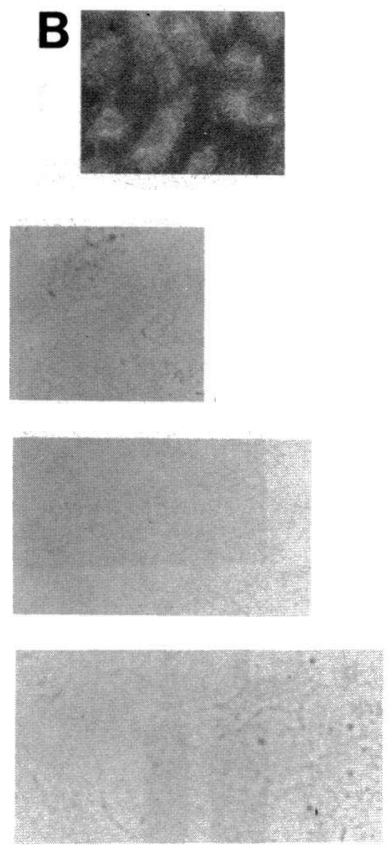

Figure 4. Immunofluorescence microscopy of Hep2 and Vero cells stained with the TSK anti-RNA pol I mAbs or scleroderma antinucleolar antibodies. Staining of Hep2 cells with IgM TSK anti-RNA pol I mAb(M61-34) $(A)$ and with control BALB/c anti-Id mAb $(B)$; colcemid-treated Vero cells stained with the same TSK mAb $(C)$; actinomycin D-treated Vero cells stained with the same TSK mAb $(D)$ or with scleroderma serum $(E)$. For $C, D$, and $E$, the same field is also shown by phase-contrast microscopy in the right. $\times 900$. 
A

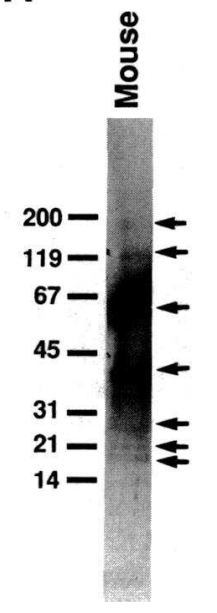

B

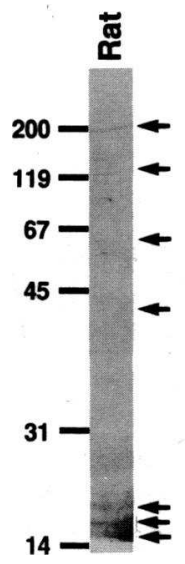

C

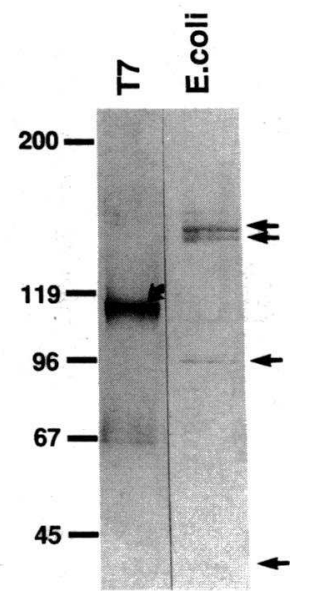

Figure 5. Silver staining of RNA polymerases from various species. Rat and mouse RNA pol I preparations, T7 and $E$. coli RNA polymerases (Pharmacia LKB Biotechnology Inc., Piscataway, NJ) were gel electrophoresed (see Methods) and silver stained (27). (A) Mouse RNA pol I-enriched preparation; (B) rat RNA pol I; $(C)$ T7 (left lane) and $E$. coli (right lane) RNA polymerases. Arrows indicate the position of the subunits. the condensed chromatin area (Fig. $4 C$, arrow). TSK mAbs also stained nucleoli of actinomycin D-treated Vero cells, showing small crescents (Fig. $4 \mathrm{D}$, arrow), but not "necklace" pattern. Scleroderma serum showed a typical necklace-shaped staining of fibrillar regions in segregated nucleolus dispersed throughout the nucleoplasm, and two small crescent-like stains in actinomycin-treated Vero cells, as expected (Fig. $4 E$, arrows). Thus, the pattern of staining with scleroderma serum is similar to that previously reported by Reimer et al. (7). These results showed that the TSK anti-RNA pol I mAbs stained intact or drug-treated cell nucleoli in the same manner as scleroderma autoantibodies did, except for the absence of necklace-type staining of actinomycin D-treated Vero cells.
Silver staining. Since the RNA pol I preparations used in our experiments originate from various sources, we confirmed their subunit composition by SDS-gel electrophoresis and silver staining (28). The results showed that mouse (Fig. $5 A$ ) and rat (Fig. $5 B$ ) RNA pol I were composed of seven subunits $(190,120,65,42,25,21$, and $20 \mathrm{kD})$ as previously described $(16,17$ ). The phage T7 (Fig. $5 C$, left lane) and $E$. coli (Fig. 5 $C$, right lane) enzymes were composed of a single polypeptide of $107 \mathrm{kD}$ and four subunits of $155,150,90$, and $37 \mathrm{kD}$, respectively $(29,30)$. It should be noted that the mouse RNA pol I preparation contained several additional bands since the material used is a phosphocellulose chromatographic fraction enriched for enzymatic activity (17).
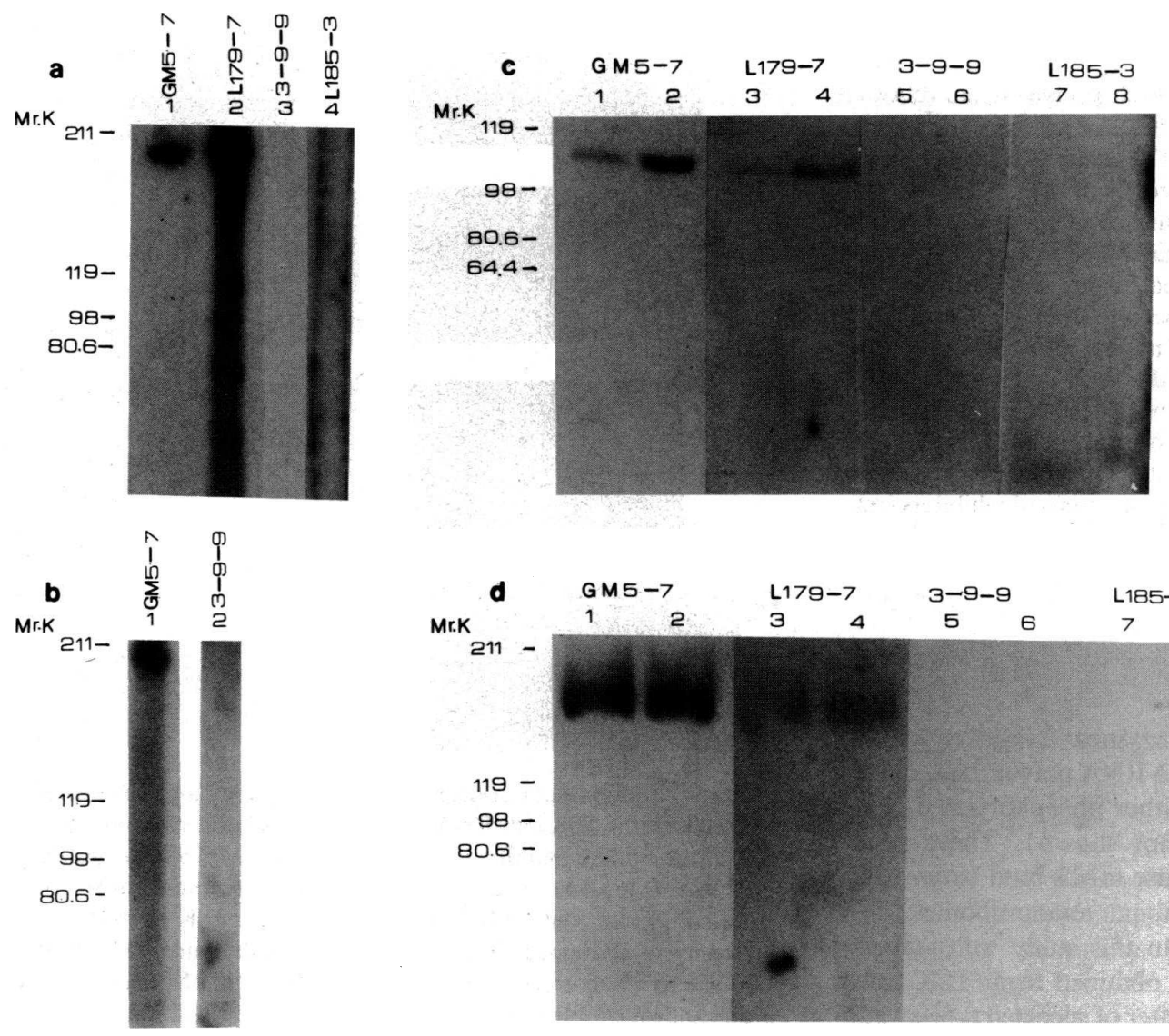

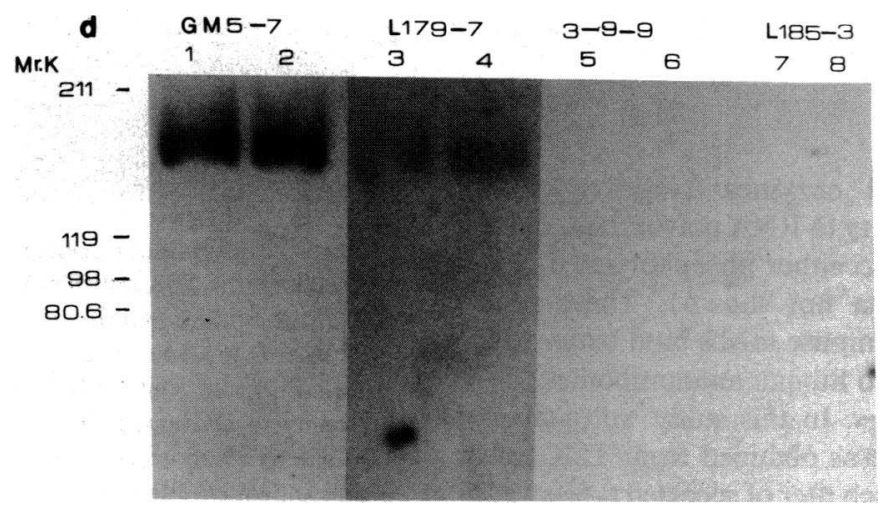

Figure 6. Analysis of the specificity of the TSK mouse anti-RNA pol I mAbs by Western blotting. (a) Western blot of rat RNA pol I developed with TSK mAbs GM5-7 (IgG), L179-7

(IgM), and control mAbs 3-9-9 ( IgG), L185-3 (IgM).

(b) Western blot of mouse RNA pol I developed with GM5-7 and control 3-9-9 mAbs. (c) Western blot of native T7 RNA polymerase (lanes 1, 3, 5, and 7) and phosphorylated T7 RNA polymerase (lanes $2,4,6$, and 8) developed with GM5-7, L179-7, 3-9-9, and L185-3 mAbs. (d) Western blot of native $E$. coli RNA polymerase (lanes $1,3,5$, and 7) and phosphorylated $E$. coli RNA polymerase (lanes $2,4,6$, and 8) developed with the mAbs shown in $c$. 
Western blot analysis. To determine the specificities of TSK mouse mAbs, we studied the binding pattern of these antibodies to the subunits of mammalian, bacterial, and viral enzymes. Western blots of rat RNA pol I (Fig. $6 a$ ) incubated with GM5-7 ( IgG) and L179-7 (IgM) mAbs showed binding to the 190-kD band. The control mAbs 3-9-9 (IgG antiidiotype against antilevan) and L185-3 (IgM anti-Fc receptor) did not bind to any of the subunits. Similarly, GM5-7 mAb showed binding to the $190-\mathrm{kD}$ polypeptide present in mouse RNA pol I. The isotype-matched control antibodies did not show any binding (Fig. $6 b$ ).

The binding of TSK mAbs to T7 and E. coli RNA polymerase was also confirmed by Western blot analysis. The results clearly showed that TSK mAbs bound to T7 RNA polymerase $(107 \mathrm{kD})$ and two larger subunits ( 155 and $150 \mathrm{kD})$ of $E$. coli enzyme. Further, these mAbs also showed higher reactivity (higher intensity) to phosphorylated enzymes compared with native enzymes. Representative results are shown in Fig. 6, $c$ and $d$. The binding of TSK mAbs GM5-7 and L179-7 is stronger to phosphorylated T7 RNA polymerase (Fig. $6 c$, lanes 2 and 4 ) and to phosphorylated E. coli RNA polymerase (Fig. $6 d$, lanes 2 and 4 ) than to native $\mathrm{T} 7$ and $E$. coli enzymes (Fig. $6 c$, lanes $l$ and 3, and $d$, lanes $l$ and 3 ). Isotype-matched control mAbs 3-9-9 and L185-3 did not show any binding to these enzymes (Fig. $6 c$, lanes 5-8, and $d$, lanes 5-8).

Effect of TSK mouse mAbs on RNA polymerase enzymatic activity. Since it has been shown previously that human antiRNA pol I antibodies obtained from SLE, MCTD, and RA inhibited the RNA synthesizing activity of the rat enzyme (6) and that PSS IgG autoantibodies suppressed the ribosomal RNA synthesis after microinjection into X-laevis oocytes (7), we studied the effect of TSK anti-RNA pol I antibodies on the enzymatic activity of RNA polymerase. As only small amounts of purified rat and mouse RNA pol I were available and because all of our mAbs bound to both mammalian and bacterial enzymes, we used $E$. coli RNA polymerase to study the effect of antibodies on enzymatic activity. On the basis of their effects on RNA synthesis, we grouped these antibodies into three categories: mAbs exhibiting an inhibitory effect (M31-1, M61-34, and L179-7; Fig. $7 A$ ); mAbs that enhance the enzymatic activity (GM38-26 or GM5-7; Fig. $7 \mathrm{~B}$ ); and mAbs that did not have any effect on the enzymatic activity (M94-32; Fig. $7 A$ ). The results obtained suggested that the TSK mouse mAbs exhibiting inhibitory activity and enhancing activity should bind to different epitopes. To verify this hypothesis, we studied the binding activity of these antibodies to $E$. coli RNA polymerase by competitive inhibition assays. This was done by incubating the radiolabeled inhibitory antibody (L179-7) with a cold enhancing antibody (GM5-7) on antigen (E. coli RNA polymerase)-coated plates. Similarly, the radiolabeled enhancing antibody was competed with the cold inhibitory antibody. The bound radioactivity was measured and the percentage inhibition was calculated. The results revealed that only homologous cold antibodies inhibited the binding of radiolabeled mAbs to the enzyme (Fig. 8). These data demonstrate that the inhibitory and enhancing antibodies recognized distinct epitopes.

$V_{H}$ and $V_{K}$ gene usage in TSK mice anti-RNA pol I mAbs. We have investigated the usage of $V$ gene family in the TSK mice anti-RNA pol I antibodies to understand the molecular basis of the autoantibody specificity and to determine whether there is a bias toward using certain $\mathrm{V}$ gene families. The results are summarized in Table II. Autoradiographs of representative Northern blots are shown in Fig. 9. 11 of $14(79 \%)$ clones use
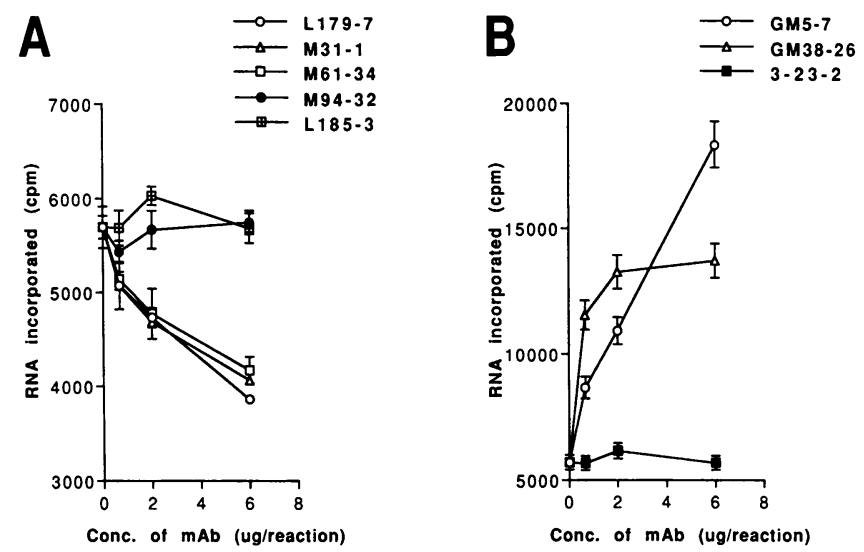

Figure 7. Effect of TSK mAbs on the RNA polymerase enzymatic activity. $0.2 \mu \mathrm{g}$ of $E$. coli RNA polymerase was preincubated with various amounts of TSK mAbs and the enzymatic activity was assayed (see Methods). $(A)$ The enzymatic activity of RNA polymerase preincubated with IgM TSK mAbs (L179-7, M31-1, M61-34, and M94-32) and an isotype control mAb (L185-3) was compared with that of the untreated enzyme. The results are expressed as mean cpm of triplicate experiments. $(B)$ Effect of IgG TSK anti-RNA pol I (GM5-7 and GM38-26) and isotype control (3-23-2) mAbs on the enzymatic activity is shown as mentioned above.

$\mathrm{V}_{\mathrm{H}} \mathrm{J} 558$ gene family, 5 of $13(38 \%)$ hybridomas use $\mathrm{V}_{\mathrm{K}} 1$, and 4 of $13(31 \%)$ use $\mathrm{V}_{\mathrm{K}} 8$ (Table II). The comparison between the expected and observed frequencies is shown in Table III. Although only a small panel of hybridomas were analyzed, our data suggest that there is a bias in the usage of both $\mathrm{V}_{\mathrm{H}} \mathrm{J} 558$, $\mathrm{V}_{\mathrm{K}} 8$, and $\mathrm{V}_{\mathrm{K}} 1$ gene families among the TSK anti-RNA pol I antibodies.

\section{Discussion}

In the present communication we demonstrate that TSK mice spontaneously produce high titers of anti-RNA pol I autoanti-
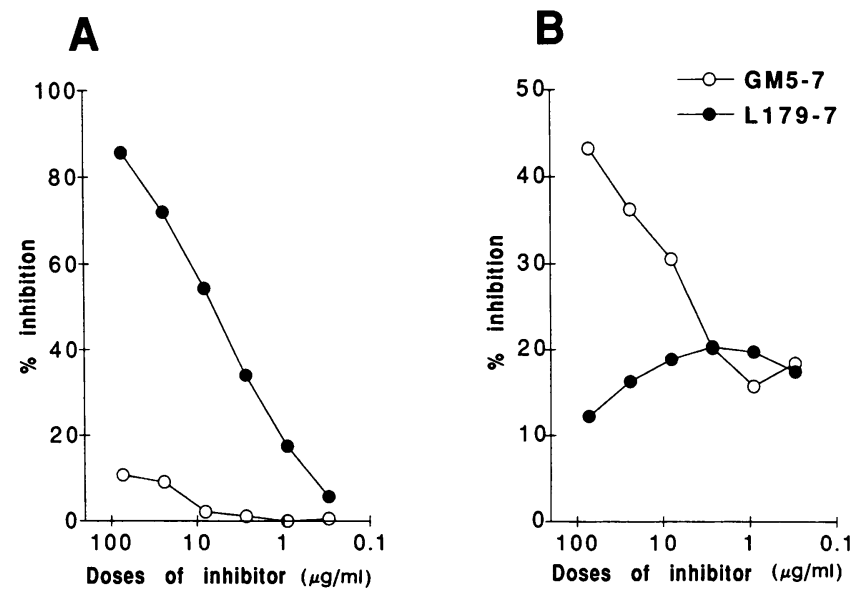

Figure 8. Competitive inhibition studies on binding activities of inhibitory and enhancing mAbs to E. coli RNA polymerase. L179-7 and GM5-7 mAbs were chosen to represent the inhibitory and enhancing types of antibodies, respectively. The mAbs were radiolabeled with ${ }^{125}$ I and used in the competitive inhibition assay. The inhibition of binding of the radiolabeled mAbs to the enzyme by cold homologous and heterologous $\mathrm{mAbs}$ was determined. The results are shown as percentage inhibition of binding of $\left[{ }^{125} \mathrm{I}\right] \mathrm{L} 179-7 \mathrm{mAb}(A)$ and $\left[{ }^{125} \mathrm{I}\right]$ GM5-7 mAb (B). 
Table II. Identification of $V$ Genes Encoding TSK Anti-RNA Pol I MAs

\begin{tabular}{llr}
\hline \multicolumn{1}{c}{ Antibody } & $\mathrm{V}_{\mathbf{H}}$ & $\mathrm{V}_{\mathbf{k}}$ \\
\hline 116A7-11 & $\mathrm{J} 558$ & 8 \\
L179-7 & $\mathrm{V}_{\text {GAM38 }}$ & 28 \\
L272-8 & 7183 & 8 \\
L341-11 & $\mathrm{J} 558$ & 1 \\
L341-22 & $\mathrm{J} 558$ & 4 \\
L435-4 & $\mathrm{J} 558$ & 1 \\
M25-4 & X24 & $\mathrm{NI}$ \\
M31-1 & $\mathrm{J} 558$ & 8 \\
M51-0 & $\mathrm{J} 558$ & 10 \\
M61-34 & $\mathrm{J} 558$ & 1 \\
M94-32 & $\mathrm{J} 558$ & 1 \\
GM3-24 & $\mathrm{J} 558$ & 23 \\
GM5-7 & $\mathrm{J} 558$ & 1 \\
GM38-26 & $\mathrm{J} 558$ & 8 \\
\hline
\end{tabular}

NI, not identified.

bodies (Fig. 1). The high frequency of hybridomas producing anti-RNA pol I antibodies observed in TSK mice (Table I) is in agreement with the above results. The presence of antiRNA pol I antibodies has been described in a number of autoimmune diseases, including scleroderma $(6,7)$. Human anti-RNA pol I autoantibodies are characterized by their ability to bind to native enzyme located in nucleoli and particularly in the fibrillar regions of nucleoli after drug-induced nucleolar segregation (7); to bind to several subunits of the enzyme $(6,7)$; to inhibit the enzymatic activity as assessed by in vitro inhibition of RNA synthesis (6) or by in vivo inhibition of ribosomal RNA synthesis after microinjection of the antibodies into the nucleus of X-laevis oocytes (7); and to show increased binding to phosphorylated enzyme (10). To determine whether these characteristics are also shared by TSK anti-RNA pol I antibodies, we prepared a large panel of mAbs and studied their properties.

The results of RIA, using purified RNA pol I enzyme preparations, show that TSK mAbs bind not only to mammalian ( rat) enzyme but also to bacterial and viral enzymes (Fig. $2 \mathrm{~A}$ ). Here we have demonstrated that rabbit and human anti-RNA pol I antibodies also bound to prokaryotic enzymes similar to TSK mouse autoantibodies.

Previous studies showed that rabbit and scleroderma antiRNA pol I antibodies gave speckled-type nucleolar staining and the staining of fibrillar regions of drug-induced segregated nucleoli $(7,31,32)$. Our immunofluorescence studies demonstrated that TSK mAbs gave a similar speckled nucleolar staining pattern with Hep2 cells (Fig. $4 A$ ), bright fluorescent dots on colcemid-treated Vero cells (Fig. $4 C$ ), and the staining of fibrillar regions of actinomycin D-treated Vero cells (Fig. 4 $D)$. However, they did not show the necklace-type nucleolar staining of actinomycin D-treated Vero cells, which was observed with scleroderma autoantibodies (7).

Reimer et al. (7) showed, by immunoprecipitation of [ $\left.{ }^{35} \mathrm{~S}\right]-$ methionine-labeled HeLa cell extracts, that scleroderma autoantibodies reacted with several subunits of rat RNA pol I. In this study the authors noted that these antibodies bound weakly to the $190-\mathrm{kD}$ subunit. Since we used highly purified ( $E$. coli, T7, and rat) or semipurified (mouse) enzymes in our
RIA, we carried out Western blot analysis to determine the subunits that were reactive with TSK autoantibodies. The results of the analysis show that TSK mAbs bind to the 190-kD subunit similar to human PSS (7), SLE (6), and MRL/lpr mice ( 8 ) autoantibodies. However, human and MRL/lpr antiRNA pol I antibodies also reacted with several smaller subunits that were not recognized by TSK monoclonal autoantibodies (Fig. 6). This distinct reactivity pattern could be attributed to the differences in the epitopes recognized by monoclonal and polyclonal autoantibodies. It is important to point out that the majority of TSK mAbs bound to the murine enzyme, which represents the putative autoantigen that was able to activate the autoreactive clones. Our studies further showed that the TSK autoantibodies bound to T7 RNA polymerase and to the two large subunits ( 155 and $150 \mathrm{kD}$ ) of $E$. coli RNA polymerase (Fig. 6). These results demonstrate that the TSK mice antibodies recognize an epitope that is conserved between species. Immunological studies using polyclonal antibodies against yeast RNA pol I showed that these antibodies cross-reacted not only with the enzymes from various strains of yeast but also with the RNA pol I from mammalian sources (33). This cross-reactivity was marked with the larger subunits of the enzyme. Previous reports have also shown the presence of significant sequence homology between the larger subunits of yeast RNA pol I and $E$. coli RNA polymerase (34). One can speculate that these common conserved epitopes may play a role in the induction of autoimmunity to these nuclear proteins. The presence of the TSK anti-RNA pol I antibodies that recognize such common epitopes suggests that the tolerance or anergic state of RNA pol I-reactive clones could be broken by the recognition of shared epitopes. It is possible that the heterologous RNA polymerase peptides (conserved or cryptic epitopes) generated by the antigen-presenting cells activate the $T$ cells, which in turn provide a "second signal" (i.e., cytokines) required for the proliferation of autoreactive B cells.

Another important property of human anti-RNA pol I autoantibodies is their ability to inhibit the enzymatic activity. In contrast to the polyclonal human anti-RNA pol I autoantibodies, which showed only inhibitory effect on the enzymatic activity $(6,7)$, TSK mouse mAbs showed three different patterns of reactivity (Fig. 7). It is likely that the clonality of mAbs enabled us to distinguish these three categories, which have not been observed in the experiments with polyclonal antibodies. The first group, represented by IgM mAbs, inhibits the enzymatic activity, indicating that these antibodies bind to an epitope associated with the catalytic site. Previous observations suggest that the larger subunits play an important role in the enzymatic activity (35). In fact, mAbs belonging to this group (L179-7) show binding to the 155- and 150-kD subunits of $E$. coli RNA polymerase and the $190-\mathrm{kD}$ protein of mammalian enzymes (Fig. 6). The second group exhibits enhancement of the enzymatic activity, which is possibly related to an allosteric effect described by Monod et al. (36). Because mAbs of this group also bind to the larger subunits of the enzymes (Fig. 6), we did competitive inhibition RIA to determine whether the $\mathrm{mAbs}$ of the first and second groups bind to different epitopes. The results clearly show that the inhibiting and enhancing mAbs recognized distinct epitopes, since the antibodies of the first group did not compete with the antibodies of the second group (Fig. 8). The third group is represented by "neutral" antibodies. These mAbs may bind to an epitope that does not affect the three-dimensional conformation of the enzyme. We have not determined the subunit specificity of these antibodies. 

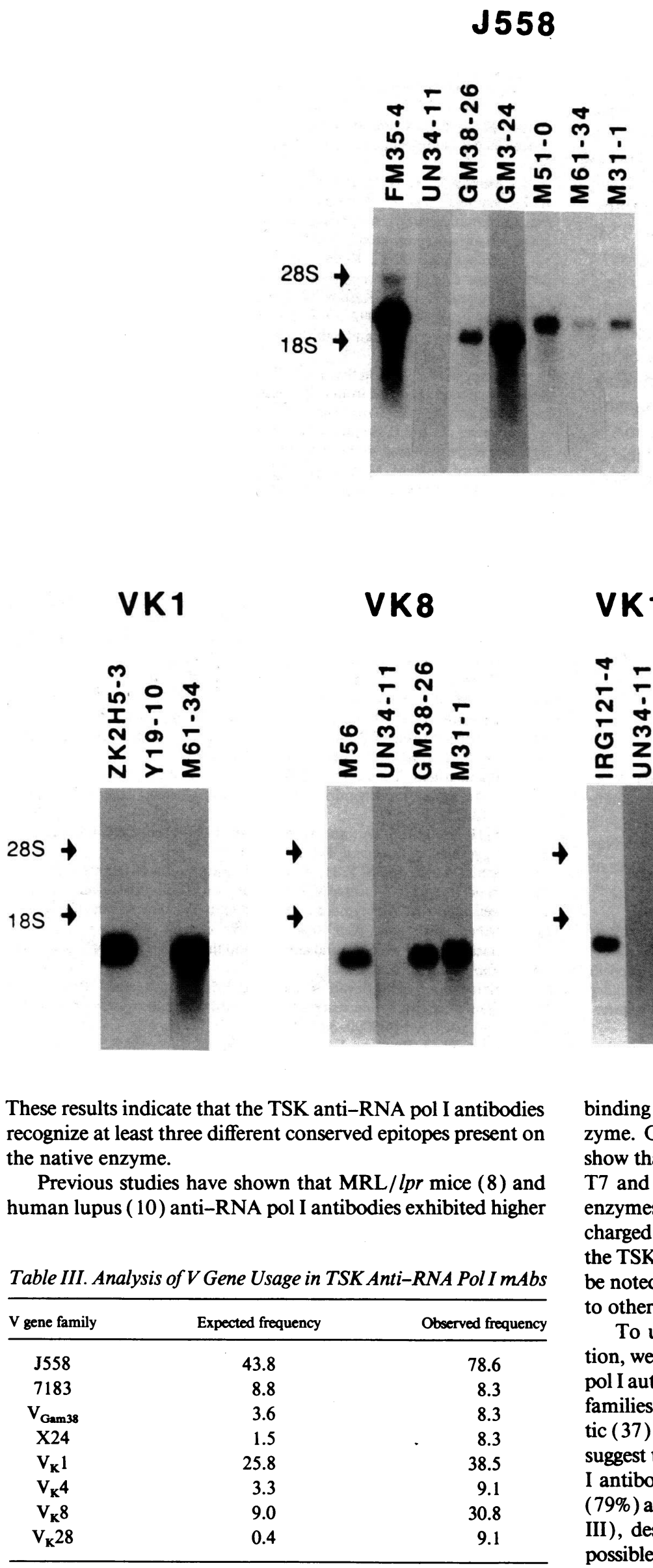

VK10

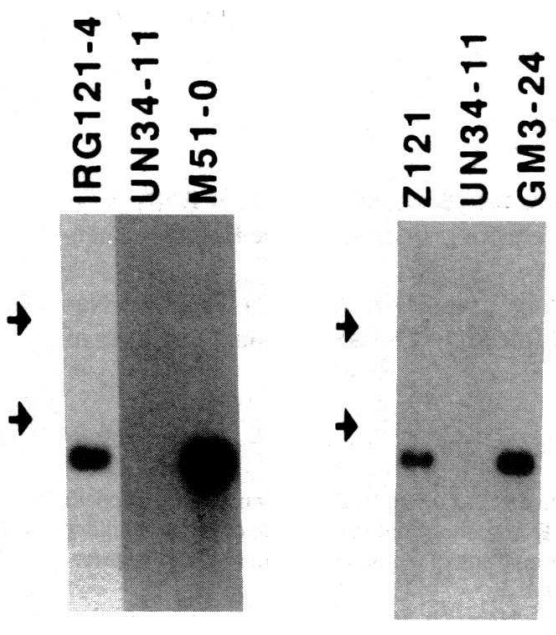

Figure 9. V gene analysis of the TSK mice hybridoma RNAs. FM354 and UN34-11 are positive and negative controls for $\mathrm{V}_{\mathbf{H}} \mathrm{J} 558$. ZK2H5-3, M56, IRG121-4, and Z121 are positive controls for $\mathrm{V}_{\mathrm{K}} 1, \mathrm{~V}_{\mathrm{K}} 8, \mathrm{~V}_{\mathrm{K}} 10$, and $V_{K}$ 23. UN34-11 and Y19-10 are negative controls for the above $V_{K}$ families.

binding to the phosphorylated enzyme than to the native enzyme. Our results of RIA and Western blot analysis indeed show that the TSK mAbs bind stronger to the phosphorylated T7 and $E$. coli RNA polymerases compared with the native enzymes (Figs. 3 and 6 ). These data suggest that negatively charged phosphate groups of the epitopes may be recognized by the TSK mouse anti-RNA pol I antibodies. However it should be noted that these mAbs did not show any significant binding to other negatively charged molecules like DNA.

To understand the genetic basis of autoantibody production, we have also studied the $V$ gene usage by TSK anti-RNA pol $I$ autoantibodies. The utilization of various $V_{H}$ and $V_{K}$ gene families in murine and human anti-DNA antibodies is stochastic (37). In contrast, our data from $V$ gene expression analysis suggest that the genes encoding the TSK mouse anti-RNA pol I antibodies are primarily derived from $\mathrm{J} 558 \mathrm{~V}_{\mathbf{H}}$ gene family (79\%) and a few $V_{K}$ families (i.e., $V_{K} 1$ and $V_{K} 8$ ) (Tables II and III), despite the smallness of the panel of hybridomas. It is possible that the common $V_{H}$ genes encoding these autoanti- 
bodies also encode an idiotype that is involved in the induction of the autoreactive clones. In fact, we have shown the presence of antiidiotypic antibodies against anti-topo I antibodies in the TSK mice (13).

In conclusion, our data demonstrate that TSK mice spontaneously produce anti-RNA pol I autoantibodies similar to those present in several autoimmune diseases $(6-8,10)$. Therefore, this mutant strain can be a valuable model for studying not only the alterations in collagen metabolism but also autoimmunity associated with connective tissue diseases. The TSK mouse anti-RNA pol I autoantibodies analyzed in the current study exhibit similar binding activity in RIA to those described by Stetler et al. (6) in SLE, RA, and MCTD. Our studies demonstrated that TSK antibodies resemble human autoantibodies in binding to the large subunit of the enzyme (7), in exhibiting increased reactivity to phosphorylated enzyme (10), in inhibiting the enzymatic activity $(6,7)$, and in staining nucleoli with speckled pattern in immunofluorescence (7). The TSK mAbs differ from scleroderma polyclonal antibodies by the lack of reactivity to smaller subunits, by exhibiting enhancing effect on the enzymatic activity in some cases, and by the lack of necklace staining pattern in immunofluorescence of actinomycin D-treated Vero cells. Proof that TSK anti-RNA pol I antibodies are identical to those that distinguish scleroderma remains to be determined. Studies in progress are aimed to determine the epitope specificity of TSK mAbs and human scleroderma mAbs, using fusion peptides obtained from cDNAs that encode for RNA pol I 190-kD subunit.

\section{Acknowledgments}

We are grateful to Dr. K. Rose for providing purified rat RNA polymerase I and Dr. B. Sollner-Webb for providing murine RNA polymerase I.

This work was supported by grant 1901-AI-24671 from the National Institute of Allergy and Infectious Disease, National Institutes of Health, Bethesda, MD.

\section{References}

1. Van de Water, J., E. Gershwin, P. Leung, A. Ansari, and R. L. Coppell. 1988. The autoepitope of the $74 \mathrm{kD}$ mitochondrial autoantigen of primary biliary cirrhosis corresponds to the functional site of dehydroliposamide acetyl transferase. J. Exp. Med. 167:1791-1799.

2. Portmann, L., N. Hamada, G. Heinrich, and L. J. Degroot. 1985. Anti-thyroid peroxidase antibody in patients with autoimmune thyroid disease: possible identity with antimicrosomal antibody. J. Clin. Endocrinol. Metab. 61:10011003.

3. Backkeskov, S., H. Aanstoot, S. Christgau, A. Reetz, M. Solimena, M. Cascalho, F. Folli, H. Richter-Olesen, and P. Camilli. 1990. Identification of the $64 \mathrm{kD}$ autoantigen in insulin dependent diabetes as GABA synthesizing enzyme glutamic acid decarboxylase. Nature (Lond.). 347:151-156.

4. Mathews, M. B., and R. M. Bernstein. 1983. Myositis autoantibody inhibits histidyl-tRNA synthetase: a model for autoimmunity. Nature (Lond.). 304:177179.

5. Karlsson, F. A., P. Burman, L. Loof, and S. Mardh. 1988. Major parietal cell antigen in autoimmune gastritis with pernicious anemia is the acid producing HK adenosine triphosphatase of the stomach. J. Clin. Invest. 81:475-479.

6. Stetler, D. A., K. M. Rose, M. E. Wenger, C. M. Berlin, and S. T. Jacob. 1982. Antibodies to distinct polypeptides of RNA polymerase I in sera from patients with rheumatic autoimmune disease. Proc. Natl. Acad. Sci. USA. 79:6499-6503.

7. Reimer, G., K. M. Rose, U. Scheer, and E. M. Tan. 1987. Autoantibody to RNA polymerase I in scleroderma sera. $J$. Clin. Invest. 79:65-72.

8. Stetler, D. A., D. E. Sipes, and S. T. Jacob. 1985. Anti-RNA polymerase I antibodies in sera of MRL $l p r / l p r$ and MRL $+/+$ autoimmune mice. J. Exp. Med. 162:1760-1770.

9. Duceman, B. W., K. M. Rose, and S. T. Jacob. 1981. Activation of purified hepatoma RNA polymerase I by homologous protein kinase NII. J. Biol. Chem. 256:10755-10758.

10. Stetler, D. A., and S. T. Jacob. 1984. Phosphorylation of RNA polymerase
I augments its interaction with autoantibodies of systemic lupus erythematosus patients. J. Biol. Chem. 259:13629-13632.

11. Green, M. C., H. O. Sweet, and L. E. Bunker. 1976. Tight-skin, a new mutation of the mouse causing excessive growth of connective tissue and skeleton. Am. J. Pathol. 82:493-507.

12. Jimenez, S. A., C. J. Williams, J. C. Meyers, and R. Bashey. 1986. Increased collagen biosynthesis and increased expression of type I and type III procollagen genes in tight-skin ( TSK) mouse fibroblasts. J. Biol. Chem. 261:657662.

13. Muryoi, T., K. N. Kasturi, M. J. Kafina, Y. Saito, O. Usuba, J. S. Perlish, R. Fleischmayer, and C. A. Bona. 1991. Self reactive repertoire of tight skin mouse: immunochemical and molecular characterization of anti-topoisomerase I autoantibodies. Autoimmunity. 9:109-119.

14. Pollard, K. M., G. Reimer, and E. M. Tan. 1989. Autoantibodies in scleroderma. Clin. Exp. Rheumatol. 7/S-3:57-62.

15. Muryoi, T., K. N. Kasturi, M. J. Kafina, D. S. Cram, L. C. Harrison, T. Sasaki, and C. A. Bona. 1992. Antitopoisomerase I monoclonal autoantibodies from scleroderma patients and tight skin mouse interact with similar epitopes. $J$. Exp. Med. 175:1103-1109.

16. Rose, K. M., D. A. Stetler, and S. T. Jacob. 1981. Protein kinase activity of RNA polymerase I purified from a rat hepatoma: probable function of $\mathrm{Mr} 42000$ and 24600 polypeptides. Proc. Natl. Acad. Sci. USA. 78:2833-2837.

17. Tower, J., and B. Sollner-Webb. 1987. Transcription of mouse rDNA is regulated by an activated subform of RNA polymerase 1 . Cell. 50:873-883.

18. Painter, C. J., M. Monestier, A. Chew, A. Dimitrui-Bona, K. N. Kasturi, C. Bailey, V. E. Scott, C. L. Sidman, and C. A. Bona. 1988. Specificities and V genes encoding monoclonal autoantibodies from viable motheaten mice. J. Exp. Med. 167:1137-1153.

19. Manheimer, A. J., and C. A. Bona. 1985. Anti-immunoglobulin antibodies VI: age dependent isotype and autoanti-gamma immunoglobulin variation during secondary immune response mechanism. Aging Hum. Dev. 30:187-199.

20. Muryoi, T., J. Andre-Schwartz, Y. Saitoh, C. Daian, B. Hall, A. DimitriuBona, R. S. Schwartz, C. A. Bona, and K. N. Kasturi. 1992. Self-reactive repertoire of tight skin (TSK/+) mouse: immunochemical and molecular characterization of anti-cellular autoantibodies. Cell. Immunol. 144:43-54.

21. Maniatis, T., E. F. Fritsch, and J. Sambrook. 1989. Molecular Cloning: A Laboratory Manual. Cold Spring Harbor Laboratory, Cold Spring Harbor, NY.

22. Kaushik, A., D. H. Schulze, F. A. Bonilla, C. A. Bona, and G. Kelsoe. 1990. Stochastic pairing of $V_{H}$ and $V_{K}$ families occurs in polyclonally activated $B$ cells. Proc. Natl. Acad. Sci. USA. 87:4932-4936.

23. Blankenstein, $T$., and $U$. Krawinkel. 1987. Immunoglobulin $V_{H}$ region genes of the mouse are organized in overlapping clusters. Eur. J. Immunol. 17:1351-1357.

24. D'Hoostelaere, L. A., and D. Klinman. 1990. Characterization of new mouse $\mathrm{V}_{\mathrm{K}}$ groups. J. Immunol. 145:2706-2712.

25. Stetler, D. A., and S. T. Jacob. 1985. Immunization of rabbits with purified RNA polymerase I induces a distinct population of antibodies against nucleic acid as well as anti-RNA polymerase I antibodies, both characteristic of systemic lupus erythematosus. Proc. Natl. Acad. Sci. USA. 82:6797-6801.

26. Hashim, G. A. 1985. Neural antigens and the development of autoimmunity. J. Immunol. 135:838-842.

27. Heinemann, S., S. Bevan, R. Kullberg, J. Lindstorm, and J. Rice. 1977. Modulation of acetylcholine receptor by antibody against the receptor. Proc. Natl. Acad. Sci. USA. 74:3090-3094.

28. Wray, W., T. Boulikas, V. P. Wray, and R. Hancock. 1981. Silver staining of proteins in polyacrylamide gels. Anal. Biochem. 118:197-203.

29. Chamberlin, M., J. McGraph, and L. Waskell. 1970. New RNA polymerase from Escherichia coli infected with bacteriophage T7. Nature (Lond.). 228:227-231.

30. Burgess, R. R. 1971. RNA polymerase. Annu. Rev. Biochem. 40:711-740.

31. Scheer, U., and K. M. Rose. 1984. Localization of RNA polymerase I in interphase cells and mitotic chromosomes by light and electron microscopic immunocytochemistry. Proc. Natl. Acad. Sci. USA. 81:1431-1435.

32. Scheer, U., B. Hugle, R. Hazan, and K. M. Rose. 1984. Drug-induced dispersal of transcribed rRNA genes and transcriptional products: immunolocalization and silver staining of different nucleolar components in rat cells treated with 5,6-dichloro- $\beta$-D-ribofuranosylbenzimidazole. J. Cell Biol. 99:672-679.

33. Huet, J., A. Sentenac, and P. Fromageot. 1982. Spot-immunodetection of conserved determinants in eukaryotic RNA polymerases. Study with antibodies to yeast RNA polymerases subunits. J. Biol. Chem. 257:2613-2618.

34. Mosrin, C., and P. Thuriaux. 1990. The genetics of RNA polymerase in yeasts. Curr. Genet. 17:367-373.

35. Sentenac, A. 1985. Eukaryotic RNA polymerases. CRC Crit. Rev. Biochem. 18:31-91.

36. Monod, J., J. P. Changeux, and F. Jacob. 1963. Allosteric proteins and cellular control systems. J. Mol. Biol. 6:306-329.

37. Bona, C. A., G. Kelsoe, V. Pascual, and J. D. Capra. 1993. Expression and pairing of VH and VL families in murine and human self-reactive antibodies. Molecular Pathology of Autoimmune Disease. C. Bona, K. Siminovitch, M. Zenetti, and A. Theophilopoulos, editors. Harwood Academic Publishers, London. 65-83. 